\title{
A graph theory approach to the dormitory room placement problem
}

\author{
Sri Efrinita Irwan ${ }^{1}$ and Triyana Muliawati ${ }^{1}$ \\ ${ }^{1}$ Mathematics Department, Institut Teknologi Sumatera, Lampung Selatan, Lampung
}

\begin{abstract}
One of the important areas in mathematics is graph theory. A graph is a mathematical structure used to model pairwise relations between objects. The theory of graph can be applied in various problems. The purpose of this paper is to solve the dormitory room placement problem using graph theory approach. In this paper, there are two factors used to determine the student room, i.e. the study program and provincial origin.
\end{abstract}

\section{Introduction}

The initial introduction of graph theory was motivated by The Seven Bridges of Königsberg problem, a historically notable problem in mathematics [1]. The city of Königsberg had seven bridges which connected two islands with the mainland via seven bridges. People staying there always wondered whether was there any way to walk over all the bridges once and only once. It was a long-standing problem until solved by Euler [2] in 1736. Euler came out with the solution in terms of graph theory. Euler pointed out that the only important feature of a route is the sequence of bridges crossed. This allowed him to reformulate the problem in abstract term. Each land mass represented by a vertex and each bridge represented by an edge. This abstraction serves to record which pair of land masses (vertices) is connected by a bridge (edge). The resulting mathematical structure is called a graph. In modern terms, a graph is known as a mathematical structure used to model pairwise relations between objects.

Graph theory is applied in various aspects such as engineering, physical, social and biological science, etc. [1]. One of the important topics in graph is graph colouring. Graph colouring has many considerable applications, such as map colouring, scheduling problem, school timetable, etc. In this paper, we discuss the application of graph colouring to the dormitory room placement problem.

Dormitory is one of the important facilities at a university. Several universities apply policies to require first-year students to live in dormitories. The existence of dormitories is often used to train student's attitude. One way that can be taken is to maintain the diversity of dormitory room residents. Example of such problems is every student in a particular room must come from a different study program and provincial origin.

\section{Definitions and facts}




\subsection{Basic graph theory}

In this subsection, we review some notions and facts related to graphs necessary for the subsequent discussion (see [3], [4], [5], and [6]). A graph is a pair $G=(V, E)$ of sets such that $E \subseteq[V]^{2}$; thus, the elements of $E$ are 2-element subsets of $V$. We always assume that $V \cap E=\emptyset$. The elements of $V$ are called the vertices and the elements of $E$ are called the edges of $G$. The vertex set of a graph $G$ denoted by $V(G)$, while its edge set denoted by $E(G)$.

Example 2.1 The graph $H$ on $V=\left\{v_{1}, v_{2}, v_{3}, v_{4}, v_{5}, v_{6}\right\}$ with the edge set $E=$ $\left\{\left\{v_{1}, v_{2}\right\},\left\{v_{1}, v_{3}\right\},\left\{v_{1}, v_{4}\right\},\left\{v_{2}, v_{5}\right\},\left\{v_{3}, v_{5}\right\}\right\}$, or can be written as $E=\left\{e_{1}, e_{2}, e_{3}, e_{4}, e_{5}\right\}$ where $e_{1}=$ $\left\{v_{1}, v_{2}\right\}, e_{2}=\left\{v_{1}, v_{3}\right\}, e_{3}=\left\{v_{1}, v_{4}\right\}, e_{4}=\left\{v_{2}, v_{5}\right\}, e_{5}=\left\{v_{3}, v_{5}\right\}$, is drawn as follows.

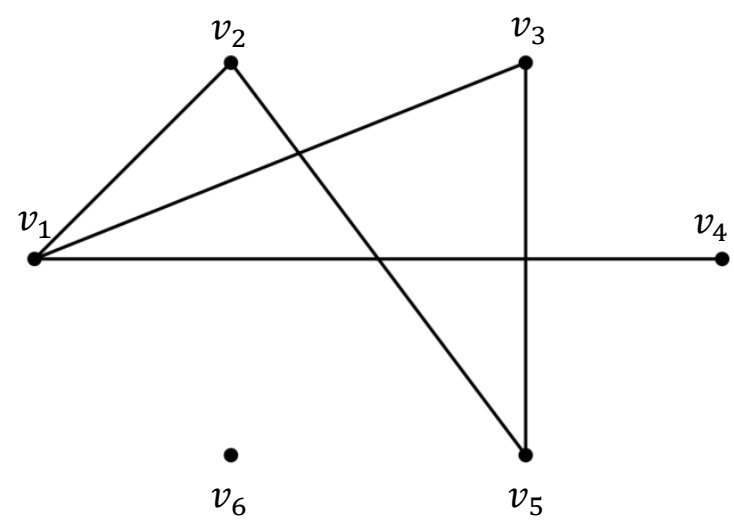

Picture 1 The graph $H$ on $V=\left\{v_{1}, v_{2}, v_{3}, v_{4}, v_{5}, v_{6}\right\}$ with the edge set $E=$ $\left\{\left\{v_{1}, v_{2}\right\},\left\{v_{1}, v_{3}\right\},\left\{v_{1}, v_{4}\right\},\left\{v_{2}, v_{5}\right\},\left\{v_{3}, v_{5}\right\}\right\}$.

The number of vertices of a graph $G$ is its order, denoted by $|G|$, its number of edges is denoted by $\|G\|$. Two vertices $v_{1}, v_{2}$ of $G$ are adjacent, or neighbours, if $\left\{v_{1}, v_{2}\right\}$ is an edge of $G$, i. e. if the vertices $v_{1}$ and $v_{2}$ connected by an edge of $G$. The number of neighbours of a vertex $v$ is called the degree of $v$.

\subsection{Graph colouring}

One of the important topics in graph theory is graph colouring. Graph colouring is divided into several types, including vertex colouring and edge colouring. In this paper, the graph colouring in question is a vertex colouring.

Formally, a vertex colouring of a graph $G=(V, E)$ is a map $c: V \rightarrow S$ such that $c\left(v_{1}\right) \neq c\left(v_{2}\right)$ whenever $v_{1}$ and $v_{2}$ are adjacent [3]. The elements of the set $S$ are called the available colours. The interesting thing about $S$ is its size. Therefore, a vertex colouring $c: V \rightarrow S$ can be restricted to $c: V \rightarrow$ $\{1,2,3, \ldots, k\}$ to say that $G$ can be coloured in $k$ different colour. The smallest positive integer $k$ satisfying the vertex colouring rule is called a chromatic number of $G$, denoted by $\chi(G)$. The chromatic number in question is related to the vertex colouring of $G$. Henceforth, the term colouring in this paper devoted to the vertex colouring of a graph.

\subsection{Welsh-Powell Algorithm}


One algorithm that can be used in graph colouring is Welsh-Powell algorithm. The Welsh-Powell algorithm consists of the following step.

1. Find the degree of each vertex.

2. List the vertices in order of descending degree.

3. Colour the first vertex in the list with the colour-1.

4. Colour every vertex not adjacent to the coloured vertices using the same colour.

5. Repeat the process to the uncoloured vertices with a new colour.

Example 2.2 The chromatic number of the graph $H$ in Picture 1 is 2.

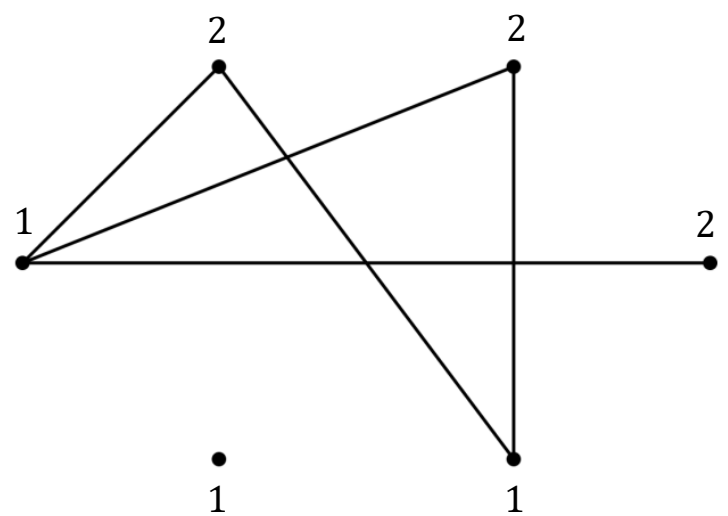

Picture 2 A vertex colouring $c: V \rightarrow\{1,2\}$ of $H$.

Based on Picture 2, it can be seen that the graph $H$ can be coloured in two colours so that every two adjacent vertices have different colours.

\section{Case Studies}

Triggered by facts explained in Section 2, it is of interest to apply the theory of graph colouring to the dormitory room placement problem. Dormitory is one of the important facilities at a university. Several universities apply policies to require first-year students to live in dormitories. In managing a dormitory, a number of universities usually utilize the existence of dormitories to train student's attitude. One way that can be taken is to maintain the diversity of dormitory room residents. Example of such problems is every student in a particular room must come from a different study program and provincial origin.

Suppose in any university, given the data of fifteen first-year students who will stay in the dormitory as follows.

Table 1 The data of fifteen first-year students who will stay in the dormitory.

\begin{tabular}{|c|c|c|c|}
\hline No & Name & Study Program & Provincial Origin \\
\hline 1 & Student-1 & Informatics Engineering & Banten \\
\hline 2 & Student-2 & Geophysical Engineering & West Java \\
\hline 3 & Student-3 & Environmental Engineering & Lampung \\
\hline 4 & Student-4 & Electrical Engineering & Lampung \\
\hline 5 & Student-5 & Environmental Engineering & Lampung \\
\hline
\end{tabular}




\begin{tabular}{|c|c|c|c|}
\hline 6 & Student-6 & Geomatics Engineering & West Sumatera \\
\hline 7 & Student-7 & Physics & North Sumatera \\
\hline 8 & Student-8 & Mathematics & North Sumatera \\
\hline 9 & Student-9 & Geophysical Engineering & North Sumatera \\
\hline 10 & Student-10 & Civil Engineering & Lampung \\
\hline 11 & Student-11 & Geomatics Engineering & Lampung \\
\hline 12 & Student-12 & Geophysical Engineering & Lampung \\
\hline 13 & Student-13 & Geomatics Engineering & Lampung \\
\hline 14 & Student-14 & Geological Engineering & Lampung \\
\hline 15 & Student-15 & Geological Engineering & South Sumatera \\
\hline
\end{tabular}

The problem that will be solved is how to arrange the student's room so that every student in a particular room must come from a different study program and provincial origin. Let $v_{i}$ be the vertex represents the Student $i$. The data in Table 1 can be represented in a graph $L$ as follows.

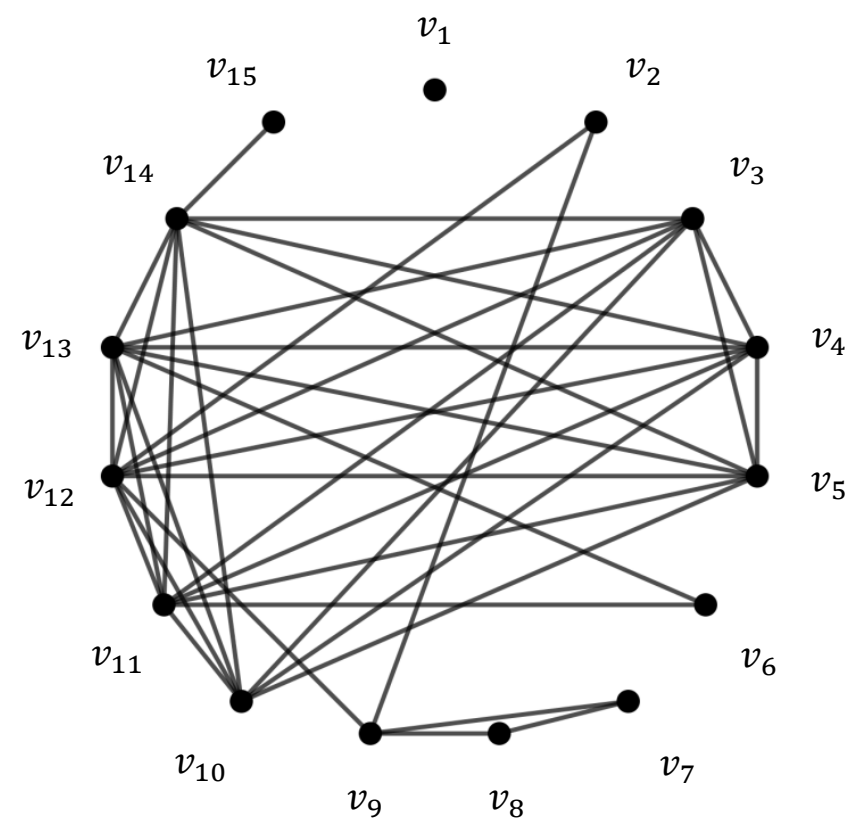

Picture 3 The graph $L$ which represents data in Table 1 .

Hence it is obtained the degree of each vertex of $L$ as in the following table.

Table 2 The degree of each vertex of $L$. 


\begin{tabular}{|c|c|c|c|c|c|c|c|c|c|c|c|c|c|c|c|}
\hline Vertex & $\boldsymbol{v}_{\mathbf{1}}$ & $\boldsymbol{v}_{\mathbf{2}}$ & $\boldsymbol{v}_{\mathbf{3}}$ & $\boldsymbol{v}_{\mathbf{4}}$ & $\boldsymbol{v}_{\mathbf{5}}$ & $\boldsymbol{v}_{\mathbf{6}}$ & $\boldsymbol{v}_{\mathbf{7}}$ & $\boldsymbol{v}_{\mathbf{8}}$ & $\boldsymbol{v}_{\mathbf{9}}$ & $\boldsymbol{v}_{\mathbf{1 0}}$ & $\boldsymbol{v}_{\mathbf{1 1}}$ & $\boldsymbol{v}_{\mathbf{1 2}}$ & $\boldsymbol{v}_{\mathbf{1 3}}$ & $\boldsymbol{v}_{\mathbf{1 4}}$ & $\boldsymbol{v}_{\mathbf{1 5}}$ \\
\hline Degree & 0 & 2 & 7 & 7 & 7 & 2 & 2 & 2 & 4 & 7 & 8 & 9 & 8 & 8 & 1 \\
\hline
\end{tabular}

By using Welsh-Powell algorithm, list of vertices in order of descending degree and the colour of each vertex of $L$ is given in the following table.

Table 3 List of vertices in order of descending degree and the colour of each vertex of $L$.

\begin{tabular}{|c|c|c|c|}
\hline No & Vertex & Degree & Colour \\
\hline 1 & $v_{12}$ & 9 & 1 \\
\hline 3 & $v_{11}$ & 8 & 2 \\
\hline 4 & $v_{13}$ & 8 & 3 \\
\hline 5 & $v_{14}$ & 8 & 4 \\
\hline 2 & $v_{4}$ & 7 & 5 \\
\hline 6 & $v_{3}$ & 7 & 6 \\
\hline 7 & $v_{5}$ & 7 & 7 \\
\hline 8 & $v_{10}$ & 7 & 8 \\
\hline 9 & $v_{9}$ & 4 & 2 \\
\hline 10 & $v_{2}$ & 2 & 3 \\
\hline 11 & $v_{6}$ & 2 & 1 \\
\hline 12 & $v_{7}$ & 2 & 1 \\
\hline 13 & $v_{8}$ & 2 & 3 \\
\hline 14 & $v_{15}$ & 1 & 1 \\
\hline 15 & $v_{1}$ & 0 & 1 \\
\hline
\end{tabular}

Therefore, the placement of student's room can be stated in the following graph.

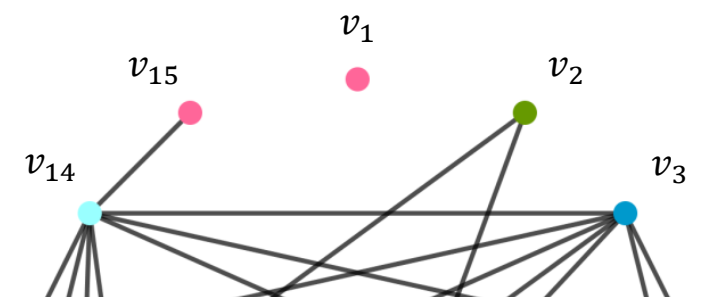


Picture 4 The vertex colouring of $L$.

From the above result, we can conclude that the chromatic number of the graph $L$ is $\chi(L)=8$. Therefore, it can be concluded that eight rooms are needed to place fifteen students so that every student in a particular room come from a different study program and provincial origin. Note that in this case, the number of students in one room is not restricted.

The solution above is not the only solution. There are alternative solutions to this problem, including the following.

Table 4 List of vertices in order of descending degree and the colour of each vertex (an alternative).

\begin{tabular}{cccc}
\hline No & Vertex & Degree & Colour \\
\hline 1 & $v_{12}$ & 9 & 1 \\
3 & $v_{11}$ & 8 & 2 \\
4 & $v_{13}$ & 8 & 3 \\
5 & $v_{14}$ & 8 & 4 \\
2 & $v_{4}$ & 7 & 5 \\
6 & $v_{3}$ & 7 & 6 \\
7 & $v_{5}$ & 7 & 7 \\
8 & $v_{10}$ & 7 & 8 \\
9 & $v_{9}$ & 4 & 3 \\
\hline
\end{tabular}




\begin{tabular}{llll}
\hline 10 & $v_{2}$ & 2 & 2 \\
11 & $v_{6}$ & 2 & 1 \\
12 & $v_{7}$ & 2 & 1 \\
13 & $v_{8}$ & 2 & 2 \\
14 & $v_{15}$ & 1 & 1 \\
15 & $v_{1}$ & 0 & 1 \\
\hline
\end{tabular}

Therefore, the placement of student's room can be stated in the following graph.

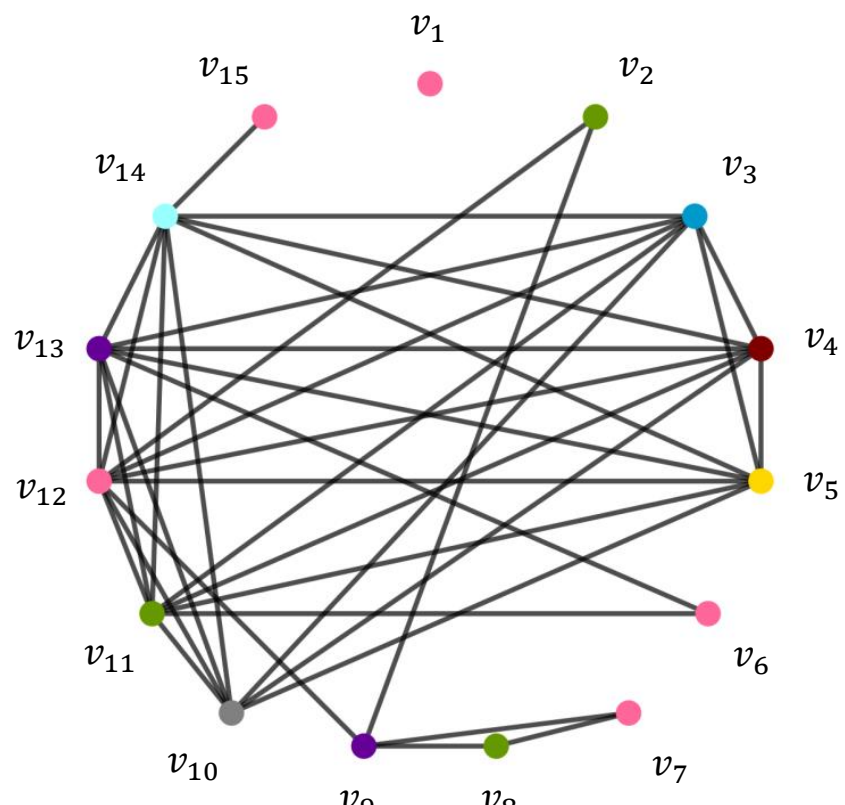

Picture 5 The vertex $v^{v_{9}}$ colouring of $L$ (an alternative).

Since the vertex $v_{1}$ is not adjacent to any vertex, there are 8 colouring options for the vertex- $v_{1}$. Therefore, the Student-1 can be in the same room with any student.

\section{Conclusion}

Based on the explanation above, it can be concluded that for the same chromatic number, there are many alternative solutions to arrange the student's room. However, based on the existing data it is known that the majority of the students who will stay in the dormitory come from Lampung. This causes the ineffectiveness of room use.

\section{References}


ICOSITER 2018 Proceeding

Journal of Science and Applicative Technology

[1] Deo N 1990 Graph theory with applications to engineering and computer science (India: Prentice Hall)

[2] Euler L 1736 Solutio problematis ad geometriam situs pertinentis Comment. Acad. Sci. U. Petrop 8 128-140

[3] Diestel R 2005 Graph theory $3^{\text {rd }}$ edition (New York: Springer-Verlag Heidelberg)

[4] Bapat R B 2010 Graph and matrices (New York: Springer London Dordrecht Heidelberg)

[5] Bondy J A and Murty U S R 1976 Graph Theory with Applications (Britain: The Macmillan Press Ltd.)

[6] Wilson R J 1996 Introduction to graph theory $4^{\text {th }}$ edition (Longman)

\section{Acknowledgments}

The authors gratefully acknowledge the helpful assistance of Hibah Mandiri Institut Teknologi Sumatera No. 134bl/IT9.C1/PP/2018 for financial support. Also, they thank referees for their valuable comments and suggestions. 